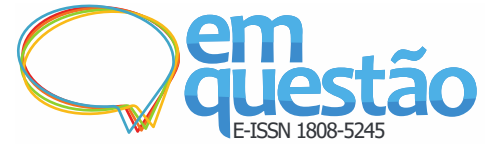

\title{
As dimensões da mediação da informação como fundamento para a mediação da leitura voltada para
} o idoso

\author{
Fausto José Silva Calheira \\ Mestre; Universidade Federal da Bahia, Salvador, BA, Brasil; \\ fausto_calheira@hotmail.com; ORCID: https://orcid.org/0000-0003-3558-3771 \\ Raquel do Rosário Santos \\ Doutora; Universidade Federal da Bahia, Salvador, BA, Brasil; \\ quelrosario@gmail.com; ORCID https://orcid.org/0000-0002-1469-0765
}

\begin{abstract}
Resumo: A prática da leitura possibilita o intercâmbio de informações importantes e apoia o desenvolvimento das capacidades intelectuais e o senso crítico dos sujeitos. A mediação da leitura também contribui com o processo de (re)construção do conhecimento e, ao mesmo tempo, visa proporcionar uma autonomia diante da interpretação e das emoções que são geradas no momento da leitura. Nessa perspectiva, este estudo evidencia o alcance das dimensões da mediação da informação propostas por Gomes (2014, 2016, 2017, 2019a, 2019b) nas atividades de mediação da leitura com os idosos. Quanto à metodologia, foi adotada a abordagem qualitativa, com o uso do método documental. Buscou-se a articulação dos aspectos teóricos, conceituais e analíticos que subsidiaram a discussão sobre as atividades de mediação da leitura com os idosos, realizadas e documentadas pelas instituições de longa permanência localizadas em Salvador, Bahia. Por meio do desenvolvimento reflexivo, considera que o mediador, ao buscar uma atuação consciente nas atividades de mediação da leitura, de modo a alcançar as cinco dimensões dialógica, estética, formativa, ética e política, contribui com o processo de ressignificação da vida dos idosos e com a apropriação da informação por parte dos sujeitos envolvidos na ação mediadora, o que favorecerá o fortalecimento do protagonismo social.
\end{abstract}

Palavras-chave: Mediação da leitura; Mediação da informação; Dimensões da mediação da informação; Idosos

\section{Introdução}

A mediação da informação é um processo em que o protagonismo social pode estar associado ao mediador e ao usuário, que devem desenvolver o "senso crítico" e a conscientização durante a ação mediadora. Os mediadores e os 
dispositivos utilizados para a mediação se articulam, e conhecê-los é fundamental. Assim, fica claro que a informação é resultado e subsídio do compartilhamento e é produzida, acessada, utilizada, organizada e apropriada no processo de encontro com o outro.

A mediação da informação só é possível por meio da leitura, que proporciona a apropriação e a construção de novas informações. Nessa perspectiva, a prática da leitura possibilita o intercâmbio de informações importantes. Ela carece de mediação e só alcança sua proficiência com a mediação consciente, por meio da qual podem emergir emoções e sentimentos de quem recebe e transmite as informações.

$\mathrm{Na}$ mediação da leitura, podem ser utilizados diferentes dispositivos informacionais, livros, fotografias, partituras, entre outros, que podem possibilitar diversas formas de diálogo e dinâmicas entre os leitores e possíveis mediadores. Por meio da leitura e suas diferentes possibilidades, descobrem-se novas formas de lazer e de integração social. Contudo, para que isso ocorra satisfatoriamente, são necessárias ludicidade e estratégias que possibilitem ao leitor mais atratividade e prazer, através de um ambiente mais acolhedor, materiais e propostas de atividades diferenciadas e planejadas. Essas características colocam a leitura em uma posição de modificadora social, porque pode interferir diretamente nas relações humanas e na conduta das pessoas e apoia o desenvolvimento das capacidades intelectuais e o senso crítico dos sujeitos. Assim, a leitura também pode proporcionar ao sujeito o desenvolvimento de seus aspectos biopsicossociais.

Diante do exposto, neste artigo, que corresponde a um fragmento da dissertação desenvolvida no curso de Mestrado em Ciência da Informação, buscou-se evidenciar o alcance das dimensões da mediação da informação propostas por Gomes $(2014,2016,2017,2020)$ nas atividades de mediação da leitura com os idosos. Quanto à metodologia, foi adotada a abordagem qualitativa, com o uso do método documental. Buscou-se a articulação dos aspectos teóricos e conceituais da mediação da informação que subsidiaram a análise e discussão sobre as atividades de mediação da leitura com os idosos no âmbito das instituições de longa permanência. 


\section{Inter-relações da mediação da informação e da mediação da leitura}

A mediação da informação, como destaca Almeida Júnior (2015), é uma ação de interferência que apoia os sujeitos no processo de acesso, uso e apropriação da informação, o que implica em compreender a mediação em uma perspectiva humanizadora, de respeito aos agentes, como também de maneira consciente e sistematizada.

No processo de mediação da informação, os ambientes, os documentos e os demais dispositivos informacionais interferem nas relações entre os sujeitos e as potencializam, além de fomenta a troca de informações e o crescimento social e cognitivo. Ao usar esses dispositivos, o mediador da informação deve ter consciência de sua importância e adaptá-los às necessidades do público que está sendo mediado. Para isso, é necessário saber negociar nas situações e entender que a mediação deve ser flexível, ou seja, diretamente condicionada à realidade e ao perfil dos sujeitos que serão mediados.

\footnotetext{
A negociação contempla, além de um modo de se relacionar, a busca por um diálogo (mesmo se árduo) na situação de divergência, ou seja, existe a consideração do outro enquanto possibilidade de troca e mudanças (dele e do "si mesmo"). Não é, portanto, ruptura, nem imposição pela força, como no caso da guerra, mas possibilidade jogada no âmbito de disputas que se valem da capacidade humana de simbolizar e de expressar-se por meio da linguagem (OLIVEIRA, 2014, p. 114).
}

A negociação pode ser entendida como uma estratégia utilizada durante a mediação da informação para auxiliar a otimizar a atividade desenvolvida. Nesse sentido, o mediador da informação tem de ter consciência de que suas ações podem sofrer influência dos sujeitos no processo de ressignificação, portanto, flexibilizar a abertura para que a fala e a ação dos sujeitos mediados sejam percebidas, contempladas nesse processo mediador e atuar de maneira sensível para identificar as diferentes iniciativas bem como as solicitações dos sujeitos que convidam a negociar suas ações.

As ações de mediação da informação só são possíveis por meio da leitura, que proporciona a apropriação e a construção de novas informações. Nessa perspectiva, a prática da leitura possibilita o intercâmbio de informações importantes. Ela carece de mediação e só alcança sua proficiência com a 
mediação consciente, por meio da qual podem emergir emoções e sentimentos de quem recebe e transmite as informações.

Segundo Boso e colaboradores (2010, p. 24), “A leitura é um importante instrumento para a vida social e cognitiva do sujeito, o que qualifica sua inserção no âmbito social, político, econômico e cultural”. Isso significa que a leitura é uma ação necessária para a realização de todas as atividades sociais, que opera de maneira individual e coletiva, e favorece a interação social e cultural, além de acionar os elementos biopsicossociais.

Ao refletir sobre mediação da leitura, Silva (2012, p. 56) afirma que os “[...] indivíduos precisam de mediação da leitura para que possam conhecer, dialogar e transitar nas linhas e nas entrelinhas dos textos literários”. É possível perceber a importância do mediador no que tange ao domínio do texto que é trabalhado, buscando explorar as diferentes possibilidades que ele pode apresentar. É por meio desse processo de mediação que se podem adotar técnicas que possibilitem o espaço da fala.

Na visão de Almeida Júnior e Bortolin (2007), a mediação da leitura pode ser compreendida como uma ação de compartilhamento. Isso significa que não basta proporcionar a circulação de textos de leitura, porque quem realiza a mediação deve ser cúmplice efetivo e afetivo do leitor e estar disposto a discutir sobre o que foi lido. Nessa perspectiva, Cavalcante (2018, p. 10) afirma que a "[...] mediação da leitura é um ato de comunicação com o outro ou consigo mesmo [...]". Assim, fica clara a importância do mediador da leitura no que diz respeito ao conhecimento do processo de mediação, já que vai fazer observações e, consequentemente, desenvolver possíveis interferências para ressignificar a ação da melhor maneira possível.

Por meio da mediação, podem-se perceber diferentes "encontros" que uma leitura pode proporcionar. Esse aspecto pode ser associado diretamente às dimensões da informação propostas e defendidas por Gomes (2014, 2017). De acordo com Gomes (2014, 2016, 2017, 2020), a mediação da informação tem cinco dimensões: a dialógica, a estética, a formativa, a ética e a política. A autora refere que, quando se alcançam as cinco dimensões de maneira 
articulada, a ação mediadora contribui para que os sujeitos se apropriem da informação, por meio da qual o protagonismo social se desenvolve.

A dimensão dialógica, proposta por Gomes (2014), é perceptível quando o mediador, em conjunto com os demais profissionais, medeia a discussão que é realizada posteriormente à atividade de leitura, seja com música, teatro ou outro dispositivo, o que faz com que os sujeitos envolvidos na ação percebam outras perspectivas relativas aos problemas por meio do processo dialógico. Pode-se, então, afirmar que as ações de mediação da leitura possibilitam a interação entre as partes e, como consequência disso, a dialogia.

As atividades de mediação da leitura podem favorecer e ampliar as percepções do mundo e os fenômenos, modificando o olhar diante do que "lê". Dessa forma, a dimensão estética, segundo Gomes (2014), é contemplada no prazer de estar no grupo e no desejo do mediador da informação e do mediado de realizarem as ações. Pode ser percebida também durante o compartilhamento de experiências entre os sujeitos, nas diferentes perspectivas sobre um mesmo problema e no surgimento de novas descobertas que favorecem o sentimento de acolhimento e integração ao grupo. Assim, é necessário o cuidado com a escolha do material que será utilizado, considerando os diferentes aspectos que o indivíduo ou grupo mediado pode apresentar.

Quando a mediação alcança sua dimensão formativa, segundo Gomes (2014, 2016), geram-se novos saberes e conhecimento por parte dos sujeitos mediadores e leitores. Essa mesma ação ocorre também com o próprio mediador, como sujeito que participa do processo e se responsabiliza por ele. Entre essas características, pode-se citar, como exemplo, a necessidade de dinamismo, de criatividade, de afetividade e de improviso, durante o ato de mediar, uma vez que a maneira como ele conduz a atividade pode ou não despertar interesse nos leitores.

Para que isso aconteça satisfatoriamente, os agentes mediadores da leitura precisam estar conscientes da responsabilidade com as atividades que desenvolverão com os sujeitos e criar estratégias, respeitando a dimensão ética da mediação, como recomenda Gomes $(2014,2017)$. Alcançar a dimensão ética é essencial durante a mediação da leitura, em que há interferências que auxiliam 
os sujeitos a se identificarem com a leitura. Nessa etapa, não se pode manipular o processo de mediação, mas provocá-lo e conduzi-lo conscientemente. O mediador precisa estar atento à fala e ser sensível ao que ouve, sem deixar que suas crenças e princípios interfiram no processo de entrega, de liberdade e de afinidade com a atividade por parte do indivíduo. É importante que as escolhas literárias humanizem a atividade desenvolvida, tornando-a um momento de prazer, de descontração, de reflexão e de (auto)crítica.

\begin{abstract}
Mediar implica a hospitalidade com a qual esse sujeito é recebido e, principalmente, acolhido, de maneira que ele se sinta à vontade para dizer o que pensa e o que busca. É sob esse olhar mediador que esse artigo se desenvolve. Um aprender proposto por diferentes olhares e formas de perceber, de apreciar e de se envolver com o mundo, com o outro e consigo mesmo (NHOQUE; WEISS; NEITZEL, 2017, p. 249).
\end{abstract}

Em seus diferentes aspectos, a mediação da leitura deve ocorrer em dispositivos que possam proporcionar aos que participam dela um ambiente melhor, para que a ação seja humanizada, e eles sejam bem acolhidos. A mediação da leitura é relevante quando os sujeitos entendem as potencialidades que lhes são oportunizadas, porque, por meio da leitura, podem ressignificar sua história, redimensionar suas ações e agir de maneira consciente, não apenas para a própria mudança, mas também para a do grupo ao qual estão vinculados, e alcança uma dimensão política, quando apoia a compreensão e a atuação dos sujeitos como protagonistas sociais.

Gomes (2016, p. 101) faz uma reflexão sobre essa dimensão, ao referir que "[...] a potência transformadora que pode decorrer da ação mediadora aponta a dimensão política da mediação da informação, o que vindica do agente mediador uma tomada de posição acerca do papel social”. Assim, pode-se entender que a dimensão política é alcançada quando os sujeitos se tornam mais conscientes e podem intervir em suas atitudes pessoais e coletivas.

A leitura possibilita que os idosos possam formar novos conceitos sobre o mundo em que vivem, sobretudo, o papel que desempenham na sociedade e na família. Para isso, torna-se necessário entender as características do universo holístico dos idosos, uma vez que o envelhecimento humano não pode ser observado somente sob a ótica da cronologia, ou seja, da idade, porquanto esse 
processo tem outro viés que abarca aspectos sociais e psicológicos. De acordo com Santos (2010, p. 1036), “[...] o ser humano idoso tem várias dimensões: biológica, psicológica, social, espiritual e outras, que necessitam ser consideradas para aproximação de um conceito que o abranja e que o perceba como ser complexo". Dessa maneira, as práticas de leitura desenvolvidas devem ser pautadas nessas particularidades.

É importante entender todos os aspectos que envolvem o universo do envelhecimento, porque, durante toda a vivência do sujeito, especialmente na juventude e em sua vida adulta, ele exerce papéis sociais que, gradualmente, vão sendo retirados. Assim, passam a ser desconsiderados, e sua representatividade no mercado (mundo) de trabalho e na família já não é mais a mesma, o que, com o tempo, pode gerar um processo de exclusão social.

Essas questões apontam para a necessidade de um olhar atento para a realidade dos idosos em alguns países, tendo em vista que seu papel social pode mudar de acordo com o país ou a comunidade em que estão inseridos. Por exemplo, um idoso que vive em um país desenvolvido pode apresentar particularidades diferentes de um que reside em um país em desenvolvimento. Nas comunidades indígenas, o envelhecimento também é visto como uma virtude, e os idosos são considerados uma fonte de conhecimento e de respeito. Esse pensamento pode divergir, a depender do local. Logo, a relação com os idosos pode se apresentar de diferentes maneiras, variando de acordo com a realidade em que eles estão inseridos. Essas realidades podem divergir, desde sua posição e importância na sociedade até os aspectos econômicos, como a aposentadoria, que fazem dessa população um universo holístico.

Ainda existe muito preconceito contra os idosos na sociedade. Com o passar dos anos, essas pessoas podem sofrer um processo de "desinserção social" e perder os vínculos e os laços que construíram ao longo da vida. Nesse contexto, as atividades direcionadas à leitura podem ser valiosas em seu processo de sociabilização. Bortolin (2010), ao tratar da mediação da leitura, defende que, associada ao lazer, essa ação é uma forma de resgatar a cidadania, minimizar as desigualdades sociais e as injustiças e melhorar a convivência na família e na comunidade. 
As práticas de leitura com a população idosa são muito importantes porque são imprescindíveis nas políticas de inclusão, contribuem para melhorar a qualidade de sua vida e proporcionam bem-estar físico, psíquico e social. São muitas as ações que envolvem a leitura e podem contribuir para o cotidiano das pessoas idosas e, consequentemente, ser desenvolvidas em diferentes dispositivos sociais, como as Instituições de Longa Permanência para Idosos (ILPI), por exemplo.

Thomaz e Valência (2012, p. 148) referem que "[...] a experiência da leitura envolve diferentes processos em sua prática e sua forma de ler, por isso é uma importante ferramenta de inclusão, que contribui para que o idoso fortaleça sua condição de ser cidadão". A leitura é um estímulo cultural na vida dos sujeitos, porque lhes proporciona lazer, possibilita que participem de diferentes atividades, resgatem a memória e construam novos laços afetivos, direcionandoos a se reconhecerem como cidadãos. Considerando as reflexões apresentadas sobre a mediação da leitura, entende-se que ela é sobremaneira importante na vida dos idosos e pode colaborar para o processo de inclusão social e bem-estar.

\section{Trajetória metodológica}

Este estudo se caracteriza como descritivo, o que, segundo Gil (2010, p. 27), “[...] têm o objetivo de descrever as características de determinada população ou fenômeno ou, então, estabelecer relações entre variáveis". Para atingir esse objetivo, foi realizada uma análise documental das atividades de mediação da leitura nas ILPI.

Dessa maneira, como a cidade de Salvador, Bahia, apresenta uma grande quantidade de ILPI, foi necessário fazer um recorte, para trabalhar com as instituições que são regulamentadas pelo Ministério Público. Assim, no ano de 2019, quando se iniciou a coleta dos dados da pesquisa, foram identificadas 32 ILPI regulamentadas em Salvador. Para alcançar os objetivos propostos, referentes ao mapeamento das atividades de mediação da leitura voltadas para os idosos e identificar as atividades e as etapas realizados nessas ações, foi preciso delinear uma subamostra, composta de 13 ILPI que realizam alguma atividade de mediação da leitura, sendo que 12 participaram efetivamente da pesquisa. 
As ILPI que fizeram parte da amostra deste estudo estão distribuídas por toda a cidade de Salvador, sendo que 7 delas na região central e as demais (5) em regiões periféricas. Apenas uma das ILPI é pública, mantida pela prefeitura da cidade, e as outras 11 ILPI são particulares. Vale ainda destacar que a faixa etária dos idosos é bem diversificada, abrangendo um público a partir dos 60 anos de idade, os quais também se distinguem no seu estado de saúde.

Um segundo critério adotado para delinear a subamostra, que corresponde à análise documental que permitiu verificar quais dimensões da mediação da informação vêm sendo alcançadas nas atividades de mediação da leitura, refere-se as ILPI que têm uma prática de mediação da leitura mais frequente e que realizam há mais tempo e de forma sistemática a mediação da leitura, correspondendo às duas (2) ILPI cuja documentação foi analisada e apresentada nesta comunicação.

Quanto à análise dos resultados, foi adotada a abordagem qualitativa, para analisar os vestígios materializados nos documentos que indicam a possibilidade de alcançar as dimensões da mediação da informação nas práticas de leitura.

\section{Apresentação e análise dos resultados}

Durante a análise documental, foram observados o tipo de documento encontrado e as informações apresentadas por duas ILPI que atenderam aos critérios da amostra, realizando uma prática de mediação da leitura mais frequente, há mais tempo, em relação às demais, e de forma sistemática. Vale destacar que a não identificação das instituições corresponde à solicitação de seus gestores. Assim, nas Instituições havia relatórios, fotografias e vídeos sobre as atividades de mediação da leitura. Nos relatórios analisados, verificou-se que, além de proporcionar momentos prazerosos e retirar o idoso da ociosidade, as atividades envolveram questões importantes, como o estímulo aos mecanismos cognitivos (memória, atenção, percepção, raciocínio, julgamento e criatividade) e a integração interpessoal, possibilitando, até mesmo, a depender da atividade proposta, o estímulo aos movimentos motores. 
O trabalho desenvolvido por essas ILPI visa integrar o idoso na sociedade, e a documentação consultada é de grande importância, pois serve para registrar tudo o que acontece e como parâmetro para a realização de futuras atividades. Assim, os relatórios presentes em ambas as Instituições descrevem as atividades e suas características, assim como a receptividade por parte dos idosos.

Nas ILPI pesquisadas, as atividades de mediação da leitura, na maioria das vezes, estão relacionadas a temas relevantes, como uma data comemorativa ou, até mesmo, situações que possam remeter à lembrança do passado. Isso é apresentado nos documentos consultados como fortalecedor do relacionamento dos idosos com outros membros das ILPI. Assim, os relatórios e os demais documentos analisados nas duas instituições selecionadas também sinalizaram o alcance das dimensões da mediação da informação por parte das atividades de mediação da leitura, a saber:

\subsection{Dimensão dialógica}

Entre as práticas que possibilitam verificar o alcance da dimensão dialógica, pode-se citar a declamação de poesias e de músicas. Essa dimensão é basilar para as atividades de mediação da leitura, por ser a comunicação fundamental para o compartilhamento e interação entre os sujeitos. Gomes (2020) defende essa proposição ao afirmar que os sujeitos podem se desvelar mutuamente, realizando reflexões com o outro e serem conduzidos ao encontro da informação, o que possibilita o surgimento de um espaço crítico, onde se fortalece uma ambiência respeitosa e geradora do conforto necessário à manifestação e à interpelação de todos.

Outras atividades que refletem o alcance da dimensão dialógica podem ser reconhecidas no relato registrado no âmbito de uma ILPI, cujo documento afirma: “Após a realização das atividades com a música e suas letras, ocorre o debate do que foi realizado, tentando extrair ao máximo as percepções que os idosos apresentam sobre o que foi desenvolvido".

As atividades de mediação da leitura que envolvem música estão presentes em todas as 12 ILPI pesquisadas na dissertação de mestrado. Dentre os 
registros encontrados dessas atividades nas 2 ILPI, que correspondem à amostra, foi possível observar relatórios, fotografias e vídeos. As 2 ILPI executam atividades de musicoterapia, buscando o entretenimento e socialização, como também o exercício mental e motor dos idosos. Os relatórios apontam que as atividades envolvendo música sempre apresentam bons resultados e que os idosos demonstram interação, o que favorece a realização de comunicação entre eles, seja oral ou gestual, evidenciando um processo dialógico.

Durante as atividades com música, foi possível verificar, através dos relatórios, que os idosos cantam, escutam e até mesmo interpretam as letras musicais, por meio de coreografias, realizando uma leitura prazerosa e dinâmica em grupo, o que, mais uma vez, favorece a comunicação e interação entre eles. Dessa forma, foi analisado um relatório de um sarau natalino que ocorreu em uma das instituições, no qual foi verificado o relato da equipe multiprofissional presente na atividade. Os profissionais descrevem nos relatórios: "O momento é proveitoso, e os idosos puderam representar canções natalinas e também declamar letras de músicas para seus colegas, foram percebidos indicadores como: participação dos idosos, interatividade e boa receptividade da atividade realizada".

No relato da atividade de mediação, pode-se perceber que, por meio da música, os idosos interagem, comunicam-se e externalizam seus sentimentos de maneira coletiva. No processo de mediação da leitura, a música pode ser reconhecida como uma expressão que deve ser interpretada pelos sujeitos de maneira consciente, visto que os idosos e os agentes mediadores compartilham informações e promovem um processo de leitura sobre si e sobre o outro por meio da música.

Segundo Paes (2007), a música ajuda no desenvolvimento do ser, porque contribui para ele compreenda sua situação e a condição real em que está inserido e, portanto, é uma forma de comunicação tão eficaz quanto a palavra falada. Esses atos de compartilhar, de se comunicar e de se expressar podem ser associados à dimensão dialógica, porquanto a música é uma forma de comunicação entre esses idosos. 
Outra atividade verificada nos documentos analisados em ambas as ILPI e percebido o alcance dessa dimensão foi a de contação de história, observada em ambas as instituições. Nos relatórios da ILPI 10, é descrito:

$\mathrm{Na}$ atividade de contação de histórias os idosos são reunidos no salão de atividades onde é distribuído os textos para que os idosos acompanhem a leitura, os textos distribuídos são de temáticas diversas, e os idosos costumam ouvir atenciosamente, interagindo depois da história apresentada.

Assim, o estudo indicou que, na maioria das atividades analisadas, a interação favorece o alcance da dimensão dialógica, que também foi percebida na interação, na crítica e na criatividade no momento da atividade do sarau. Nos vídeos analisados nas ILPI, foi possível verificar essas condutas por parte dos idosos e toda a criatividade na declamação das poesias.

\subsection{Dimensão estética}

O alcance da dimensão estética da mediação da informação (GOMES 2014, 2016, 2017, 2020) também pode ser evidenciado em algumas atividades de mediação da leitura nas ILPI, pois, nessas ações, há um movimento multidirecional ligado à geração de experiências no encontro com a informação, com quem a produziu e com outros sujeitos que também foram em busca de acessá-la e interpretá-la. Em um dos documentos analisados na Instituição 4, em que foi realizada uma atividade de declamação de poesias e de músicas, tem-se a seguinte informação: "Os idosos após a realização da atividade costumam agradecer a todos os profissionais envolvidos, e demonstram-se motivados e agradecidos pelo desenvolvimento de ações que mudem a sua rotina."

Pode-se perceber, no trecho retirado do relatório da ILPI, a emoção por parte dos idosos, bem como suas demonstrações de gratidão por causa da atividade de mediação da leitura realizada e o prazer de se (re)conhecer e participar da atividade de mediação da leitura, reforçando os princípios da dimensão estética. Essa interação nas atividades de mediação da leitura, que proporciona o prazer de estar no coletivo e o desejo de externalizar sentimentos e conhecimentos, podem ser percebidos também na Figura 1. 


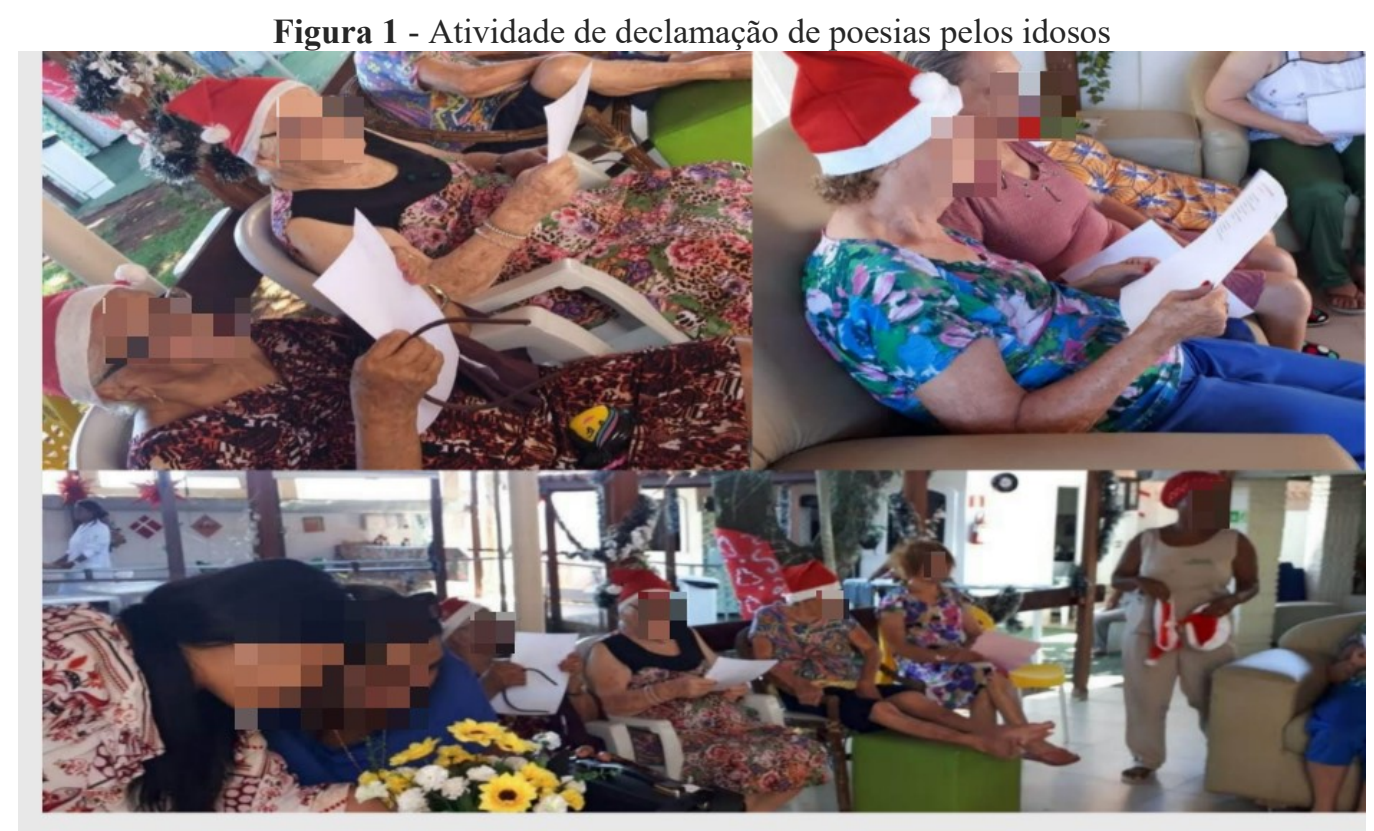

Fonte: Dados da pesquisa.

No registro fotográfico acima, é possível verificar a participação dos idosos durante as atividades de declamação de poesias e perceber que outros membros da Instituição também participam das atividades propostas, o que acaba por fortalecer os vínculos existentes entre os idosos e a comunidade externa. No relatório da ILPI, consta a seguinte informação: "Os idosos costumam se emocionar e compartilhar experiências pessoais com o grupo, sendo esse então um momento de partilha no qual a rotina é alterada, trazendo um maior dinamismo no dia do idoso institucionalizado".

Esse despertar de emoções possibilita que o idoso mude sua rotina e se sinta parte das atividades que são realizadas, podendo partilhar suas emoções e sentimentos. Essa partilha contribui por torná-lo parte integrante das atividades que são desenvolvidas, uma vez que elas podem possibilitar a integração do grupo.

A citação do relatório evidencia que a mediação da leitura pode ressignificar a vida dos idosos. Pode-se inferir que a expressão de emoção é uma demonstração do prazer de estar em grupo e do desejo de que essa prática continue, porque eles se sentem motivados. Assim, as atividades de mediação da leitura atingem a dimensão estética da mediação da informação, defendida por (GOMES 2020), pois é possível ressignificar e transformar a vida dos idosos, 
para que eles possam sentir prazer em compartilhar e vivenciar novas atividades, relembrar momentos de sua vida e almejar novas ações para seu futuro.

Outra perspectiva que indica o alcance da dimensão estética é a do ambiente onde acontecem as mediações, que colabora com a realização das atividades propostas, quando é ornamentado de acordo com a atividade ou o período festivo no qual será desenvolvida. Nos relatórios da instituição 08 é possível verificar fotos e descrição sobre como as atividades são organizadas, conforme se pode observar abaixo: "O ambiente no qual acontecem as atividades com os idosos é sempre decorado com a temática que envolve a atividade. O clima do espaço muda e sempre reflete no humor dos idosos, que se sentem motivados com o ambiente modificado".

A dimensão estética também foi verificada na análise dos documentos que envolvem as atividades com a música, as quais também têm registros imagéticos, como fotografias e vídeos, que podem reforçar os elementos descritos nos relatórios, nos quais é possível sinalizar uma postura proativa do idoso no decorrer da atividade: "Os idosos costumam interagir e pegar o microfone utilizado na atividade para executar os comandos solicitados pela equipe, indo sempre além do que a equipe solicita, trazendo um maior dinamismo e participação nas atividades desenvolvidas." (ILPI 05).

Essa proatividade pode ser percebida quando o idoso assume a ação e vai além do que é proposto durante a mediação. Essa atitude pode indicar um sentimento de liberdade, de prazer e de desejo de vivenciar aquele momento de maneira espontânea, o que pode indicar o alcance da dimensão estética da mediação da informação nas atividades de mediação da leitura com os idosos. Essa perspectiva de vivenciar o prazer e o sentimento de liberdade por meio das atividades de leitura também foi referida por Costa e Bortolin (2007), ao defenderem que, quando se lê por prazer, pode-se ter como resultado a liberdade intelectual, pois, no momento da criação, é possível deixar a imaginação livre, o que evidencia a dimensão estética da mediação da informação.

Nos registros analisados, verificou-se a articulação entre dispositivos que são adotados nas atividades de medição da leitura. A música, a dança e a contação de histórias foram realizadas conjuntamente para estimular os idosos a 
participarem da mediação da leitura. Segundo os relatórios analisados, eles poderiam desenvolver, com base nos textos discutidos durante uma contação de história, desde o exercício da oralidade - ao cantar ou declamar letras de músicas - até movimentos corporais, como a dança, durante a atividade de mediação da leitura com a música. Essa articulação entre atividades envolve o desenvolvimento cognitivo, físico e emocional dos idosos, o que pode ser verificado tanto nos vídeos e nas fotografias do evento quanto no relatório da ILPI 06:

Os idosos, depois da contação de histórias sobre músicas do nordeste, elaboraram uma apresentação de dança, na qual o objetivo era encenar uma música regional. A partir da apresentação é possível verificar o entendimento por parte dos idosos no que tange a cultura e musicalidade da nossa região, os idosos demonstraram alegria e interação.

Vê-se, então, que uma atividade realizada pode dar origem a outra e envolver diferentes recursos. A criação faz parte desses momentos, e isso pode ser observado não só por parte da equipe mediadora como também dos idosos. Essa perspectiva apresentada pode favorecer o alcance da dimensão estética. Gomes (2020) defende que, "Quando os sujeitos acionam a dimensão estética, podem proporcionar um espaço de voz, o exercício da crítica e o debate, em que a expressão e a interpelação garantem um espaço fundamental no que foi executado".

Nos vídeos e nas imagens analisadas, a música faz parte das atividades de mediação da leitura e proporciona importantes alterações no comportamento dos idosos, que demonstram expressões de alegria em seus rostos. Assim, ao associar a música às atividades, o mediador possibilita uma leitura intra e interpessoal dos sujeitos em relação aos seus sentimentos e aos dos outros, cujas expressões emocionais podem ser compartilhadas e refletidas conjuntamente, o que amplia o desejo de estar no coletivo e atinge a mediação da leitura e a dimensão estética da mediação da informação (GOMES 2014, 2016, 2020).

Essas observações indicam que os idosos alcançaram a dimensão estética, quando se envolvem no grupo, expressam o desejo de participar e, por meio da leitura reflexiva das letras e da sonoridade musical, manifestam sentimentos. Assim, pode-se perceber que a dimensão estética é atingida - ou 
existem indícios de seu alcance - em várias atividades de mediação da leitura com os idosos.

\subsection{Dimensão formativa}

Quanto à dimensão formativa, foram identificados indícios do seu alcance nos documentos analisados. Em um relatório, consta que a atividade de mediação da leitura envolveu pintura, em que foram utilizados giz de cera e tinta guache. $\mathrm{O}$ objetivo dessa atividade foi favorecer, através de desenho livre, de pintura ou de desenhos, o resgate de memórias, gestos e expressões da representação da história de vida de cada um dos idosos participantes e de tratar de temas atuais, visando contribuir para que os idosos estejam sempre informados e adquiram novos conhecimentos. Na atividade de mediar a leitura descrita, os sujeitos podem se apropriar de novas informações e ressignificar as a que já tinham acesso, (trans)formando-se e ampliando suas percepções e conhecimentos.

A Figura 2 registra a atividade de mediação da leitura que integrou a pintura e o desenho como ações para registrar as percepções dos idosos.

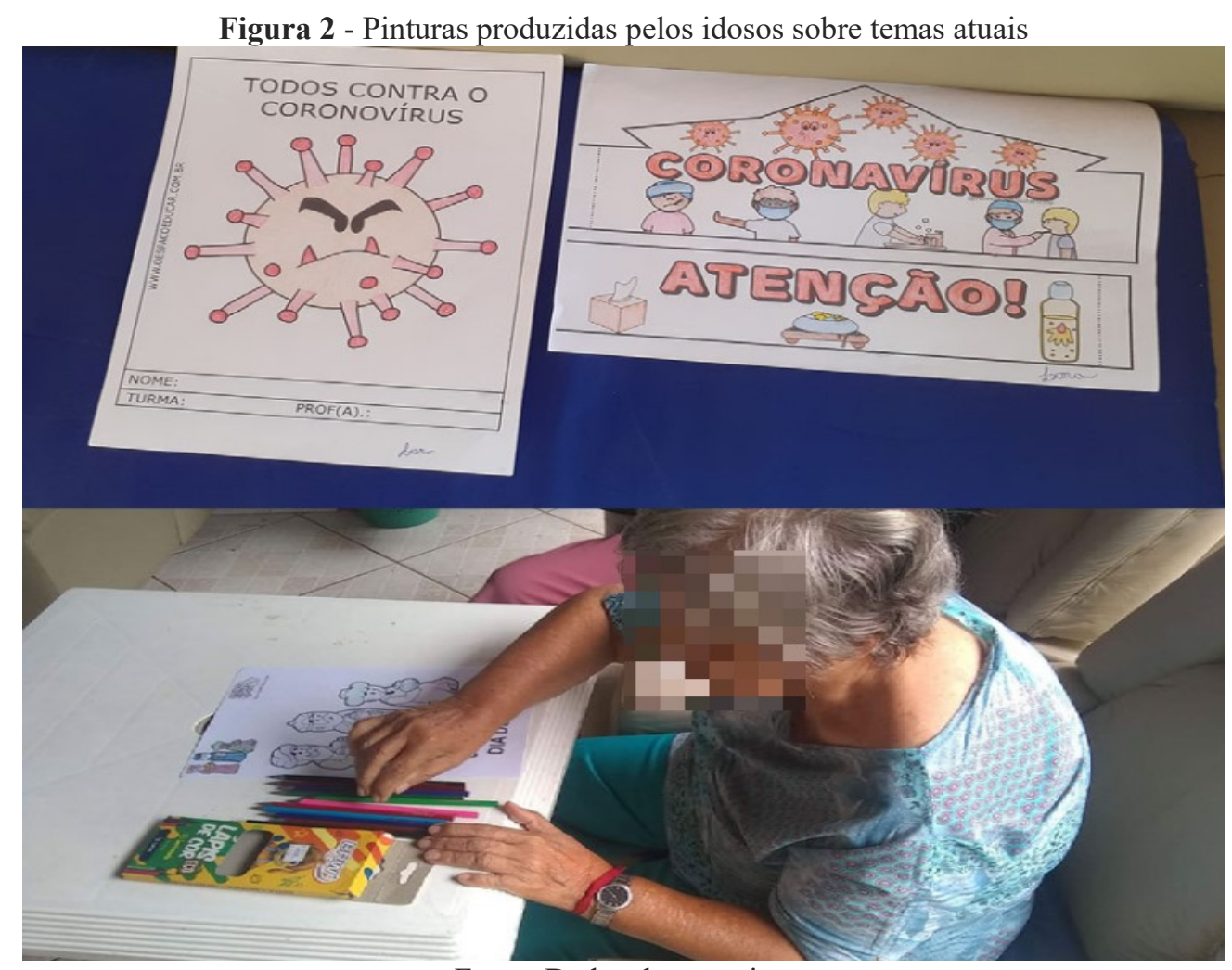

Fonte: Dados da pesquisa. 
Na imagem acima, vê-se uma ação de pintura desenvolvida na ILPI, a qual possibilita o desenvolvimento dos aspectos cognitivos do idoso, porque estimula sua coordenação motora e busca tratar de temas atuais, como, por exemplo, o coronavírus, mantendo-os atualizados e conscientes sobre a realidade atual e as possíveis modificações sofridas na dinâmica da sociedade.

Essa atividade demonstra que os agentes mediadores de leitura se preocupam com o acesso à informação e a possibilidade de os idosos continuarem desenvolvendo um olhar crítico sobre a realidade. Dessa maneira, pode-se identificar indício do alcance da dimensão formativa, visto que, tanto nas imagens e nos vídeos quanto nos relatórios consultados, foi possível observar que, durante a realização do trabalho de pintura e de desenho com os idosos, eles foram estimulados a desenvolver uma percepção acerca do seu contexto social.

As atividades de mediação da leitura podem ter diferentes finalidades para o idoso e ser utilizadas com fins terapêuticos ou até mesmo de lazer. Costa e Bortolin (2007) reforçam a importância do lazer nessa faixa etária, porque entendem que essa é uma maneira de resgatar a cidadania da pessoa idosa e de reduzir as desigualdades e as injustiças, bem como de melhorar os aspectos que abrangem a convivência na família e na comunidade. Esse fato pode ser destacado também no Art. 20 do Estatuto do Idoso, que diz sobre o direito à educação, cultura, esporte, lazer, diversões, espetáculos, produtos e serviços que respeitem sua peculiar condição de idade.

O alcance da dimensão formativa também pode ser observado nas descrições dos relatórios, que elucidam a atividade de declamação de poesias e músicas. Essa dimensão fica evidente quando é verificada a criação de produtos por parte dos idosos, uma vez que muitas poesias declamadas são criadas por eles. Durante as atividades de declamação de poesia mencionadas nos relatórios analisados, foi possível observar que os idosos interagem nessas atividades, a maioria participa e tenta apresentar o que produziu, sempre fazendo reflexões sobre um momento que vivenciou e situações que estão vivenciando no presente. No relatório de uma das instituições, é possível verificar essa ação: "Os idosos demonstram e relatam a importância de cultivar amigos, incentivar o 
respeito e participar das atividades em grupo e individual de acordo com suas habilidades, muitos relatam que se sentem parte do processo.”.

\subsection{Dimensão ética}

A dimensão ética também pode ser observada na participação dos idosos na atividade de declamação de poesias, apresentada nas fotografias e nos relatórios. $\mathrm{Na}$ análise documental dessa atividade, constatou-se que ela pode fortalecer a ideia de inclusão dos idosos, independentemente de suas possíveis limitações. Essa inclusão é um fator que indica o alcance da dimensão ética durante o desenvolvimento dessas atividades, pois possível perceber nos registros não apenas os idosos que estão envolvidos, mas também outros membros da ILPI e familiares.

A Figura 3 ilustra o registro da atividade de mediação da leitura que associa a contação de história, a música e a dança.

Figura 3 - Apresentação de dança das idosas com base no texto apresentado na contação de história

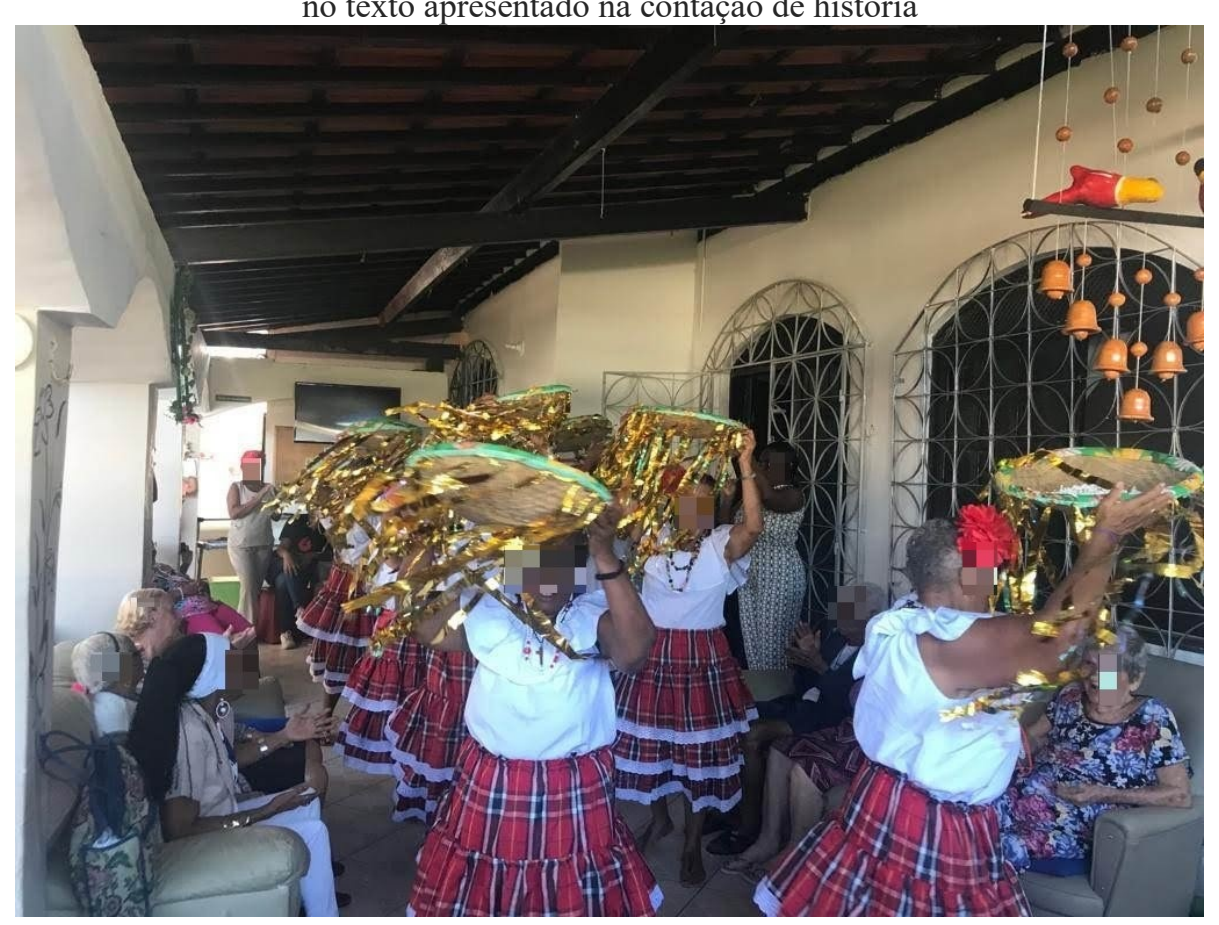

Fonte: Dados da pesquisa.

A atividade de mediação da leitura registrada na imagem acima refere-se à apresentação de dança das idosas com base em textos apresentados durante a contação de história. Essa atividade tratou de questões socioculturais, como 
aspectos identitários da dança regional. Dessa maneira, a mediação da leitura possibilitou o processo de reflexão sobre o diferente, na perspectiva da alteridade, e não se limitou a possibilitar que as idosas tivessem o prazer de dançar e de (re)viver aspectos presentes em suas memórias afetivas. Assim, a mediação da leitura pode favorecer o conhecimento dos diferentes aspectos que envolvem o outro, proporcionando o respeito e o cuidar. Gomes (2014) defende que a mediação da informação está atrelada ao cuidado, portanto, a mediação da leitura também evidencia esse aspecto.

O respeito e a possibilidade de interação entre os "diferentes" na atividade de mediação da leitura demonstra uma conduta próxima à defendida por Gomes (2020) quando trata da dimensão ética da mediação da informação, que, segundo a autora, é caracterizada como uma ação interacionista e dialética, na qual a diversidade pode ser manifestada por meio da voz e do espaço onde ocorre a atividade, o que acaba por construir um processo problematizador, em que se devem respeitar as diferenças e, ao mesmo tempo, garantir um local de expressão e interpelação de todos os participantes, favorecendo o alcance da dimensão ética.

\subsection{Dimensão política}

A dimensão política apresentou fortes indícios nos documentos analisados em uma das instituições referente às atividades que envolvem a contação de histórias. $\mathrm{Na}$ atividade investigada, foram utilizados textos que abordavam o tema 'pandemia de corona vírus', iniciada no ano de 2020. Os relatórios descrevem que, durante a atividade, foram lidos textos que envolviam esse assunto e as possíveis implicações e modificações que a pandemia trouxe para a sociedade. Do relatório analisado na ILPI 02, foi extraído o seguinte fragmento:

Os idosos observaram atenciosamente a leitura realizada e ao final buscaram trazer suas contribuições e pensamentos sobre a situação atual. Alguns idosos demonstraram o entendimento sobre a gravidade da situação que atinge o mundo, e também sobre a necessidade de prevenção. Foi-se criado a partir das ideias colocadas pelo grupo de idosos participante da atividade, uma live para os familiares, onde os idosos puderam participar e conscientizar seus familiares sobre a importância da prevenção e cuidados com os moradores de uma ILPI. 
O entendimento apresentado por parte dos idosos sobre a realidade do país e a criação de um evento para discutir e conscientizar seus familiares sobre o tema indicam que a dimensão política foi alcançada. Nessa (re)ação com os mediadores da leitura, eles se tornam mais conscientes e passam a interferir na vida do outro, para resguardar sua vida e o bem coletivo. Essa dinâmica percebida na mediação da leitura se aproxima do que foi defendido por Gomes (2020), ao salientar que a mediação da informação proporciona condições para a tomada de consciência por parte dos sujeitos que fazem acontecer essa ação, uma consciência de sua condição de sujeitos políticos ao abandonarem a máscara da neutralidade. Assim, os idosos não se limitaram às barreiras de distanciamento social, mas adotaram meios para interagir, conscientizar e apoiar o outro, interferindo e contribuindo com o bem coletivo.

Vale destacar que, apesar de ser o único registro que indica a possibilidade de se alcançar a dimensão política, essa ação demonstra o caminho fértil que os idosos podem percorrer no agir protagonista, de realizar a ação consciente e que transforma sua realidade e a vida do outro. Assim, as atividades de mediação da leitura podem apoiar os idosos e os agentes mediadores na realização de ações que reflitam sobre a inclusão, a justiça e a equidade social.

\section{Considerações finais}

A análise dos resultados sinaliza que as dimensões da mediação da informação apresentam indícios de sua abrangência a partir de alguns apontamentos das atividades desenvolvidas. O compartilhamento dos saberes e das vivências durante a mediação da leitura, bem como a interação, a crítica e a criatividade dessa ação, podem indicar o alcance da dimensão dialógica.

Quando o estímulo cognitivo dos idosos é desenvolvido, pode-se inferir que eles percebem a própria transformação e a dos demais sujeitos e sentem prazer de se (re)conhecer e participar da ação de leitura. Nesse caso, evidenciase as dimensões estética e formativa. Essa última dimensão é identificada quando os idosos buscam, por meio das atividades de mediação da leitura, mais informações sobre temas de interesse, novas possibilidades de compartilhar seus saberes, como também criar novos dispositivos a partir da atividade. 
O fato de incluir os idosos, mesmo os que têm alguma necessidade que demande um cuidado específico, como, por exemplo, com a seleção prévia de materiais para a realização da atividade, pode-se indicar que, nesse ato consciente de inclusão que evita a marginalização e a segregação, existe uma possibilidade de alcançar a dimensão ética. Dessa forma, as dimensões da mediação da informação estão imbricadas em todo o processo da mediação da leitura, desde sua organização e seu planejamento até o resultado final e sua ressignificação.

A dimensão estética também foi evidenciada na Figura 1, quanto aos indicadores relacionados à criação de laços afetivos, que podem ser entendidos como a possibilidade de priorizar a ampliação do processo solidário, interpretativo e criativo. Essa dimensão é relacionada ao prazer que os idosos e as idosas sentem durante a mediação da leitura.

A dimensão política tem como forte indicador, apresentado na imagem 1, o sentimento de pertencimento que os idosos desenvolvem, que pode fazer com que tenham mais consciência de sua realidade e influenciar suas atitudes pessoais e coletivas. Essa dimensão também foi observada a partir do momento em que as ILPI, por meio das atividades de mediação da leitura, proporcionaram uma melhor qualidade de vida aos idosos e fortaleceram seu papel social.

Dessa maneira, fica evidenciado que as atividades de mediação da leitura desenvolvidas nas ILPI estimulam uma tomada de consciência da realidade que os idosos vivem e o desenvolvimento de um sentimento de pertencimento por parte deles, ou seja, as atividades de mediação da leitura podem estar relacionadas à autodescoberta, ao compartilhamento de conhecimentos e à apropriação das informações por parte dos idosos, atuando em seu bem-estar e em seu contexto biopsicossocial. Assim, ratifica-se a relevância dos mediadores da leitura buscarem o desenvolvimento de ações conscientes que integrem esses idosos e os possibilite também um (re)conhecimento sobre si e uma ressignificação da sua vida social. 


\section{Financiamento}

Este estudo foi financiado pela Fundação de Amparo à Pesquisa do Estado da Bahia (FAPESB).

\section{Referências}

ALMEIDA JÚNIOR, Oswaldo Francisco de. Mediação da informação: um conceito atualizado. In: BORTOLIN, Sueli; SANTOS NETO, João Arlindo dos; SILVA, Rovilson José da (Org.). Mediação Oral da Informação e da Leitura. Londrina: ABECIN, 2015. p. 9-32.

ALMEIDA JÚNIOR, Oswaldo Francisco de; BORTOLIN, Sueli. Mediação da informação e da leitura. In: SEMINÁRIO EM CIÊNCIA DA INFORMAÇÃO, 2., 2007, Londrina. Anais eletrônicos [...]. Londrina: Universidade Estadual de Londrina, 2007.

BORTOLIN, Sueli. Mediação Oral da Literatura: a voz dos bibliotecários lendo ou narrando. 2010. 233 f. Tese (Doutorado em Ciência da Informação) Departamento de Ciência da Informação, Faculdade de Filosofia e Ciências, Universidade Estadual Paulista, Marília, 2010.

BOSO, Augiza Karla et al. Aspectos cognitivos da leitura: conhecimento prévio e teoria dos esquemas. Revista ACB: Biblioteconomia em Santa Catarina, Florianópolis, v. 15, n. 2, p. 24- 39, jul./dez. 2010.

CAVALCANTE, Lídia Eugenia. Mediação da leitura e formação do leitor. In: NETTO, Raymundo; CAVALCANTE, Lídia Eugenia (Org.). Curso de Formação de Mediadores da Leitura. Fortaleza: Fundação Demócrito Rocha, 2018.

COSTA, Clarissa Benassi Gonçalves da; BORTOLIN, Sueli. A terceira idade e as ações de leitura dos bibliotecários de duas instituições. In: SEMINÁRIO EM CIÊNCIA DA INFORMAÇÃO, 2., 2007, Londrina. Anais eletrônicos [...]. Londrina: Universidade Estadual de Londrina, 2007.

GIL, Antônio Carlos. Como Elaborar Projetos de Pesquisa. 5. ed. São Paulo: Atlas, 2010.

GOMES, Henriette Ferreira. Comunicação e informação: relações dúbias, complexas e intrínsecas. In: MORIGI, Valdir; JACKS, Nilda; GOLIN, Cida. (Org.). Epistemologias, Comunicação e Informação. Porto Alegre: Sulina, 2016. p. 91-107.

GOMES, Henriette Ferreira. A dimensão dialógica, estética, formativa e ética da mediação da informação. Informação \& Informação, Londrina, v. 19, n. 2, p. 46-59, maio/ago. 2014. 
GOMES, Henriette Ferreira. Mediação da informação e protagonismo social: relações com vida ativa e ação comunicativa à luz de Hannah Arendt e Jürgen Habermas. In: GOMES, Henriette Ferreira; NOVO, Hildenise Ferreira (Org.). Informação e Protagonismo Social. Salvador: EDUFBA, 2017. p. 27 44.

GOMES, Henriette Ferreira. Mediação da informação e suas dimensões dialógica, estética, formativa, ética e política: um fundamento da Ciência da Informação em favor do protagonismo social. Informação \& Sociedade: estudos, João Pessoa, v. 30, n. 4, p. 1-23, out./dez. 2020.

GOMES, Henriette Ferreira. Protagonismo social e mediação da informação. Logeion: Filosofia da Informação, Rio de Janeiro, v. 5, n. 2, p. 10-21, mar. 2019.

NHOQUE, Janete Ribeiro; WEISS, Cláudia Suéli; NEITZEL, Adair de Aguiar. Mediação de leitura: o olhar dos alunos sobre o trabalho com textos literários. Educação em Foco, Juiz de Fora, n. 30, p. 247-266, jan./abr. 2017.

OLIVEIRA, Amanda Leal de. A negociação cultural: um novo paradigma para a mediação e a apropriação da cultura escrita. 2014. 250 f. Tese (Doutorado em Ciência da Informação) - Programa de Pós-graduação em Ciência da Informação, Escola de Comunicações e Artes, Universidade de São Paulo, São Paulo, 2014.

PAES, Camila da Rocha. Idosos Moradores de Instituição de Longa Permanência e a Influência das Narrativas Literárias e Musicais: estudo de caso. 2007. 85 f. Monografia (Bacharelado em Biblioteconomia) Departamento de Ciência da Informação, Faculdade de Biblioteconomia e Comunicação, Universidade Federal do Rio Grande do Sul, Porto Alegre, 2007.

SANTOS, Silvana Sidney Costa. Concepções teórico-filosóficas sobre envelhecimento, velhice, idoso e enfermagem gerontogeriátrica. Revista Brasileira de Enfermagem, Brasília, DF, v. 63, n. 6, p. 1035-1039, dez. 2010.

SILVA, Maria da Conceição. A Mediação da Leitura: o caso do Curso Sesc Vem Ler. 2012. 147 f. Dissertação (Mestrado em Ciência da Informação) Programa de Pós-graduação em Ciência da Informação, Instituto de Ciências da Informação, Universidade Federal da Bahia, Salvador, 2012.

THOMAZ, Fabiane; VALENCIA, Maria Cristina Palhares. Inclusão social do idoso através da leitura. CRB8 Digital, São Paulo, v. 1, n. 5, p.148-160, 2012. 


\title{
The dimensions of mediation of information as the foundation for mediation of reading for the elderly
}

\begin{abstract}
The practice of reading enables the exchange of important information and supports the development of the intellectual capacities and the critical sense of the subjects. Reading mediation also contributes to the process of (re)construction of knowledge and, at the same time, aims to provide autonomy in face of the interpretation and emotions that are generated at the time of reading. In this perspective, this study aimed to highlight the scope of the dimensions of information mediation proposed by Gomes (2014, 2016, 2017, 2019a, 2019b) in reading mediation activities with the elderly. As for the methodology, the qualitative approach was adopted, using the documentary method. We sought to articulate the theoretical, conceptual and analytical aspects that supported the discussion on reading mediation activities with the elderly, carried out and documented by long-term institutions located in Salvador, Bahia. Through reflective development, it could be considered that the mediator, when seeking a conscious performance in reading mediation activities, to reach the five dialogical, aesthetic, formative, ethical and political dimensions, starts to contribute to the process of resignification of the elderly's life and with the appropriation of information by the subjects involved in the mediating action, which will favor the strengthening of social protagonism.
\end{abstract}

Keywords: Mediation of reading; Information mediation; Dimensions of information mediation; Elderly

Recebido: 09/04/2021

Aceito: 02/07/2021

\section{Declaração de autoria}

Concepção e elaboração do estudo: Fausto José Silva Calheira e Raquel do Rosário Santos.

Coleta de dados: Fausto José Silva Calheira e Raquel do Rosário Santos.

Análise e interpretação de dados: Fausto José Silva Calheira e Raquel do Rosário Santos.

Redação: Fausto José Silva Calheira e Raquel do Rosário Santos.

Revisão crítica do manuscrito: Fausto José Silva Calheira e Raquel do Rosário Santos. 


\section{Como citar:}

CALHEIRA, Fausto José Silva; SANTOS, Raquel do Rosário. As dimensões da mediação da informação como fundamento para a mediação da leitura voltada para o idoso. Em Questão, Porto Alegre, v. 28, n. 2, e-112916, abr./jun. 2022. https://doi.org/10.19132/1808-5245282.112916

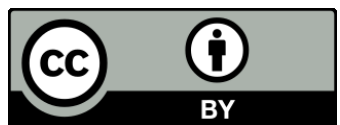

